\title{
Deferasirox, an oral iron chelator, with gemcitabine synergistically inhibits pancreatic cancer cell growth in vitro and in vivo
}

\author{
Shuhei Shinoda ${ }^{1}$, Seiji Kaino ${ }^{1}$, Shogo Amano ${ }^{1}$, Hirofumi Harima ${ }^{1}$, Toshihiko \\ Matsumoto ${ }^{1,2}$, Koichi Fujisawa ${ }^{1}$, Taro Takami ${ }^{1}$, Naoki Yamamoto ${ }^{1}$, Takahiro \\ Yamasaki $^{2}$ and Isao Sakaida ${ }^{1}$ \\ ${ }^{1}$ Department of Gastroenterology and Hepatology, Yamaguchi University Graduate School of Medicine, Yamaguchi, Japan \\ ${ }^{2}$ Department of Oncology and Laboratory Medicine, Yamaguchi University, Graduate School of Medicine, Yamaguchi, Japan \\ Correspondence to: Taro Takami, email: t-takami@yamaguchi-u.ac.jp \\ Keywords: deferasirox; iron chelator; gemcitabine; pancreatic cancer; ribonucleotide reductase
}

Received: March 10, $2017 \quad$ Accepted: April 28, $2018 \quad$ Published: June 19, 2018

Copyright: Shinoda et al. This is an open-access article distributed under the terms of the Creative Commons Attribution License 3.0 (CC BY 3.0), which permits unrestricted use, distribution, and reproduction in any medium, provided the original author and source are credited.

\section{ABSTRACT}

Objectives: Iron is an essential element for cell proliferation and growth processes. We have reported that deferasirox (DFX), an oral iron chelator, showed antiproliferative activity against pancreatic cancer cells. This study aimed to elucidate the effects of combination of gemcitabine (GEM), standard chemotherapy for pancreatic cancer, and DFX in vitro and in vivo.

Results: GEM+DFX showed antiproliferative activity and induced apoptosis in pancreatic cancer cells in vitro. GEM+DFX suppressed xenograft tumor growth and induced apoptosis without any serious side effects compared with control, GEM, and DFX (average tumor volume: control $697 \mathrm{~mm}^{3}$ vs GEM $372 \mathrm{~mm}^{3}, p<0.05$; GEM $372 \mathrm{~mm}^{3}$ vs GEM+DFX $234 \mathrm{~mm}^{3}, p<0.05$ ). RRM1 and RRM2 protein levels were substantially reduced by DFX in BXPC-3 in vitro.

Conclusion: GEM+DFX has significant anticancer effects on pancreatic cancer cell through RR activity suppression.

Methods: BxPC-3, a human pancreatic cancer cell line, was used in all experiments. Cellular proliferation rate was measured using 3-(4,5-dimethylthiazol-2yl)-5-(3-carboxymethoxyphenyl)-2-(4-sulfophenyl)-2H-tetrazolium, inner salt assay. Apoptosis was evaluated by flow cytometry and by measuring caspase $3 / 7$ activity with luminescence assay. In the tumor xenografts in nude mice models, when five weeks after engraftment, drug administration began (day 0 ). After treatment for 21 days, the mice were sacrificed and the tumors were excised. Apoptotic cells in xenografts were evaluated by terminal deoxynucleotidyl transferase deoxyuridine triphosphate nick-end labeling assay. Protein levels of ribonucleotide reductase (RR) subunit 1 (RRM1) and RR subunit 2 (RRM2) in BxPC-3 cells were assessed by western blot in vitro.

\section{INTRODUCTION}

Pancreatic cancer is a highly lethal disease, in which mortality closely parallels incidence. The 5-year survival rate of pancreatic cancer, including resectable cases, is not more than $10 \%$ [1]. For patients with unresectable pancreatic cancer, chemotherapy is the mainstay of treatment. During the last two decades, gemcitabine 
(GEM), a nucleoside analog of deoxycytidine, has been the standard chemotherapeutic agent for pancreatic cancer [2]. Recently, new combination chemotherapies, such as regimens combining fluorouracil, irinotecan, oxaliplatin, and leucovorin (FOLFIRINOX) [3] or albumin-bound paclitaxel with GEM [4], have been reported. However, while combination chemotherapies have shown therapeutic advantages over single-agent GEM, they also have a high incidence of side effects. Moreover, more than half of pancreatic cancer patients are diagnosed at an age of $\geq 65$ years [5]. Hence, GEM remains a key drug, and a new chemotherapeutic strategy for pancreatic cancer is still required, especially for those with refractory cancer, because of side effects and/or advanced age.

Iron is an essential element for cell proliferation and growth processes [5]. Iron chelators, which are commonly used for iron-overload disease, have shown antiproliferative effects for numerous kinds of cancer [6]. Additionally, iron chelators have lower incidence of side effects because they are not classified as anticancer drugs. We have conducted the world's first pilot study of deferoxamine (DFO) therapy in patients with advanced hepatocellular carcinoma and subsequently reported the efficacy of this approach [7]. However, DFO cannot be administered orally, thereby limiting its clinical application. Recently, deferasirox (DFX), a new oral iron chelator, has been developed. We found that DFX has antiproliferative activity against pancreatic cancer cells in vitro and in vivo; however, DFX did not induce apoptosis sufficiently [8]. We have also reported that the combination of DFX and sorafenib exerts a stronger inhibitory effect in hepatocarcinogenesis compared with DFX alone [9]. Against this background, we evaluated the combination of GEM and DFX against pancreatic cancer for the first time. Here, we showed the antiproliferative activity of the combined treatment of GEM+DFX against pancreatic cancer cells.

\section{RESULTS}

\section{Antiproliferative activity of GEM+DFX against pancreatic cancer cells in vitro}

BxPC-3 was incubated with either the vehicle control or the indicated concentrations of DFX for $72 \mathrm{~h}$; subsequently, cell survival rates were measured using the 3-(4,5-dimethylthiazol-2-yl)-5(3-carboxymethoxyphenyl)-2-(4-sulfophenyl)-2H-

tetrazolium, inner salt (MTS) assay. The survival rate of cells decreased in a dose-dependent manner when treated with DFX (Figure 1A). Then, we examined the antiproliferative activity of the combined treatment of GEM+DFX against BxPC-3. As shown in Figure 1, the IC50 value of DFX in BxPC-3 was $22.1 \pm 2.1 \mu \mathrm{M}$. Thus, BxPC-3 was exposed to $\operatorname{GEM}(0,5,10,20,39$, $78,156,312 \mathrm{nM}$ ) with $20 \mu \mathrm{M}$ DFX or without DFX for
$72 \mathrm{~h}$. The cell survival rates are shown in Figure 1B. The antiproliferative activity of the combined treatment of $20 \mathrm{nM}$ GEM and $20 \mu \mathrm{M}$ DFX was significantly higher than that of GEM alone (Figure 1C).

\section{Apoptosis in pancreatic cancer cells treated with GEM + DFX in vitro}

Apoptosis was evaluated by measuring caspase 3/7 activity with luminescence assay. Considering the results of cell proliferation assay, we added $20 \mathrm{nM}$ GEM, $20 \mu \mathrm{M}$ DFX, or $20 \mathrm{nM}$ GEM and $20 \mu \mathrm{M}$ DFX to each well. The caspase $3 / 7$ activity of the combined treatment of GEM+DFX was significantly higher than that of GEM alone (Figure 2A). Flow cytometry using PI and Annexin $\mathrm{V}$ staining was employed in the apoptosis analysis. The number of late apoptosis cells of the combined treatment of GEM+DFX was significantly higher than that of GEM alone (Figure 2B, 2C).

\section{Tumor growth suppression and apoptosis without serious side effects in vivo by GEM + DFX}

The antiproliferative activity of the combined treatment of GEM+DFX against pancreatic cancer cells was assessed in vivo using $\mathrm{BxPC}-3$ pancreatic cancer xenografts in $\mathrm{BALB} / \mathrm{c}$ nude mice. The average tumor volumes of the control, GEM, DFX, and GEM+DFX groups were $697 \pm 244,372 \pm 136,372 \pm 166$, and 234 $\pm 107 \mathrm{~mm}^{3}$, respectively (Figure 3A). A significantly suppressed xenograft tumor growth without serious side effects, such as weight loss or altered serum biochemistries (albumin, AST, ALT, Cre, and AMY), was observed in the GEM+DFX group (Table 1). Moreover, in the blood sample examinations, the DFX and GEM+DFX groups had significantly decreased serum ferritin levels $(16.0 \pm$ 4.1 and $14.6 \pm 3.8 \mathrm{ng} / \mathrm{ml}$, respectively) compared with the control $(26.8 \pm 15.1 \mathrm{ng} / \mathrm{ml})$ and GEM $(26.1 \pm 9.4$ $\mathrm{ng} / \mathrm{ml}$ ) groups (Table1). Tumor cells were assessed for apoptosis using a terminal deoxynucleotidyl transferasedeoxyuridine triphosphate nick-end labeling (TUNEL) kit, which labels apoptotic nuclei with a fluorescent maker. As shown in Figure 3B and 3C, tumor cells in the GEM+DFX group had a significantly increased apoptosis.

\section{Suppression of RRM1 and RRM2 protein expression by DFX}

Ribonucleotide reductase (RR) subunit 1 (RRM1) and RR subunit 2 protein levels in BxPC-3 cells were assessed by western blot. The average RRM1 protein band intensity (intensity/control) of the GEM, DFX, and GEM+DFX groups were $1.90 \pm 0.20,0.48 \pm 0.09$, and $0.32 \pm 0.08$, respectively. The average RRM2 protein band intensity (intensity/control) of the GEM, DFX, and GEM+DFX groups were $1.74 \pm 0.34,0.64 \pm 0.19$, and 
$0.43 \pm 0.16$, respectively. The RRM1 and RRM2 protein expression levels were significantly upregulated in the cells treated with GEM, but were significantly down-regulated in the cells treated with DFX and GEM+DFX (Figure 4A4C). These results showed that RRM1 and RRM2 protein levels were substantially reduced by DFX in BxPC-3.

\section{Panc-1 showed same trend as BxPC-3 in antiproliferative activity and RRM1 protein expression levels}

Panc-1, another cell line, was also evaluated. Panc-1 was also incubated with either the vehicle control or the indicated concentrations of DFX for $72 \mathrm{~h}$; subsequently, cell survival rates were measured using the MTS assay. As shown in Figure 5A, the IC50 value of DFX in Panc1 was $23.4 \pm 3.7 \mu \mathrm{M}$. Thus, Panc-1 was exposed to GEM $(0,1,2,4,8,16,31,63,125,250 \mathrm{nM})$ with $20 \mu \mathrm{M}$ DFX
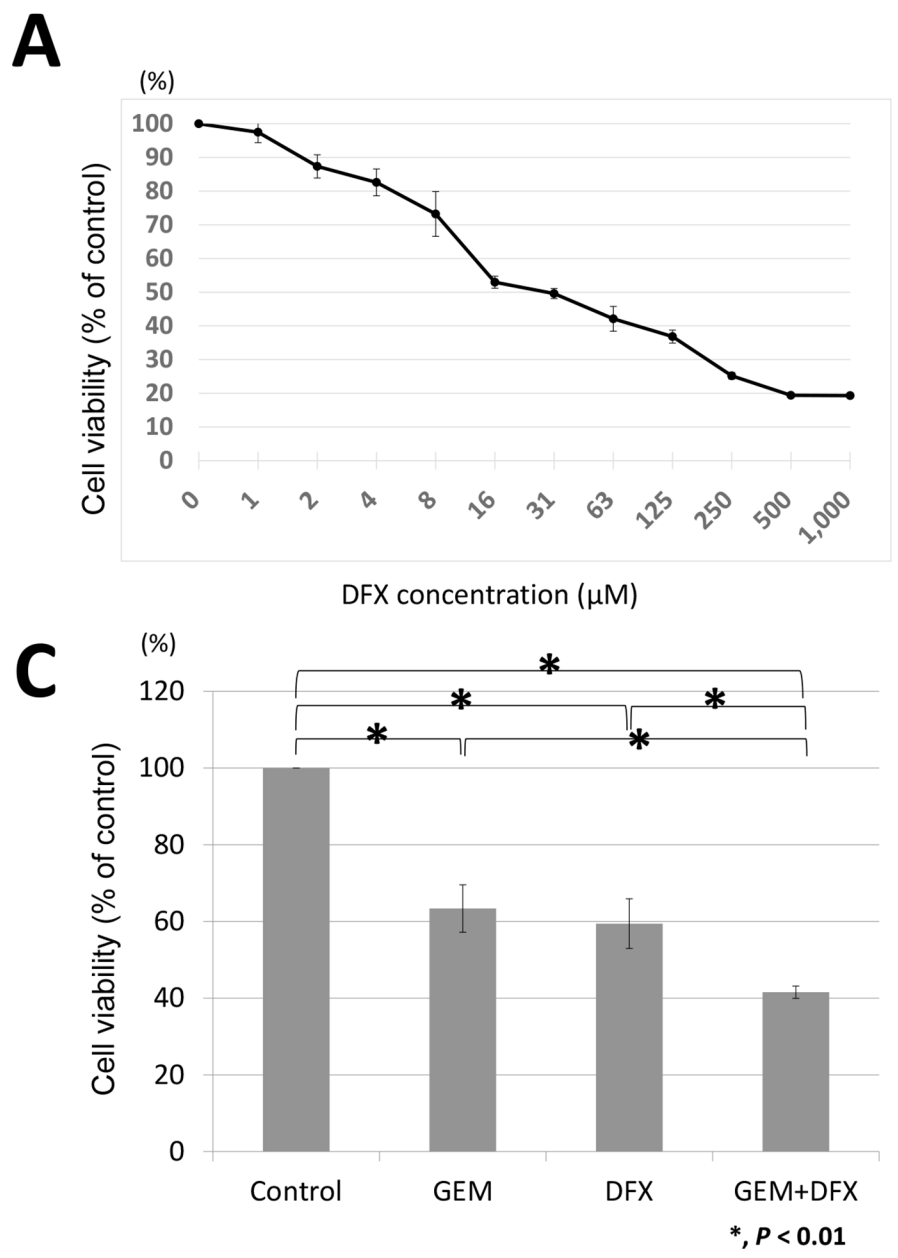

or without DFX for $72 \mathrm{~h}$. The cell survival rates are shown in Figure 5B. The antiproliferative activity of the combined treatment of $20 \mathrm{nM}$ GEM and $20 \mu \mathrm{M}$ DFX was significantly higher than that of GEM alone (Figure 5C). RRM1 protein levels in Panc-1 cells were also assessed by western blot. RRM1 protein expression levels of Panc1 were downregulated in the cells treated with DFX and GEM+DFX (Figure 5D). These results showed that Panc-1 also followed same trend as BxPC-3.

\section{DISCUSSION}

GEM still remains a key drug for pancreatic cancer today; however, the most important problem is gemcitabine resistance. Many studies have tackled gemcitabine resistance [10]. The levels of GEM's active derivate gemcitabine triphosphate must comprise a sufficient proportion of the cellular pool of

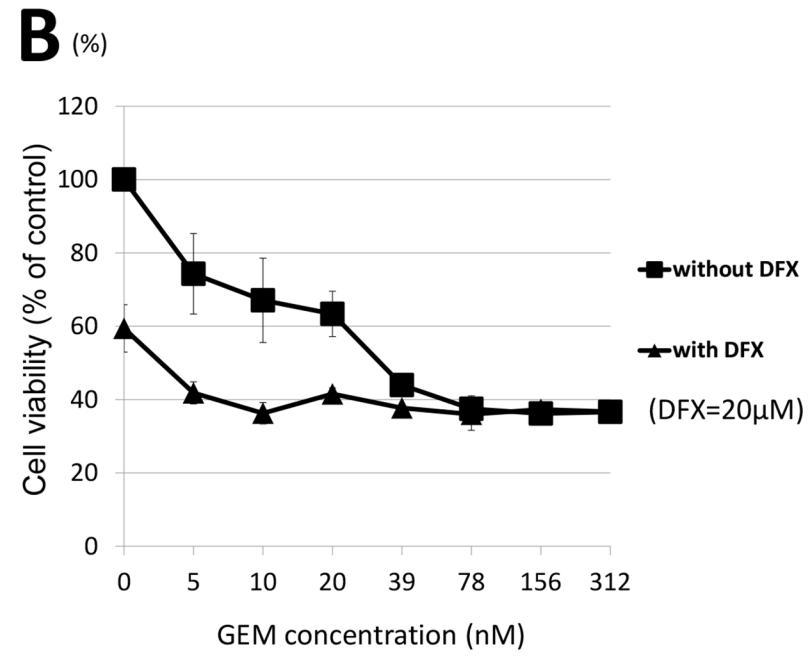

Figure 1: GEM+DFX has antiproliferative activity against pancreatic cancer cells in vitro. (A) DFX inhibited the proliferation of BxPC-3 cells. The cells were treated with DFX for $72 \mathrm{~h}$. The viability of BxPC-3 cells incubated with DFX decreased in a dose-dependent manner. Data are presented as mean \pm SD $(n=3)$. (B) GEM and GEM+DFX inhibited the proliferation of BxPC-3 cells. The cells were treated with GEM and/or DFX for $72 \mathrm{~h}$. The viability of BxPC-3 cells incubated with GEM and/or DFX decreased in a dosedependent manner. Data are presented as mean $\pm \mathrm{SD}(n=3)$. (C) The antiproliferative activity of the combined treatment of $20 \mathrm{nM}$ GEM and $20 \mu \mathrm{M}$ DFX for BxPC-3 was significantly higher than that of GEM alone. Data are presented as mean $\pm \operatorname{SD}(n=3)$. 
deoxynucleotides (dNTPs) to be efficiently incorporated into the DNA. Expansion of naturally occurring dNTPs in the nucleotide pool leads to GEM resistance. Moreover, RR plays an essential role in the maintenance of the deoxyribonucleotide pool, and RR upregulation also leads to GEM resistance $[11,12]$. This resistance mechanism was shown to be clinically relevant in lung $[13,14]$ and breast [15] cancer. In pancreatic cancer, interestingly, RRM1 levels were inversely correlated with patient survival [16].

The antiproliferative activity of iron chelators was first demonstrated in leukemia in 1986 [17, 18], and the antiproliferative activity of DFX has been investigated in various cancers [7, 8, 19-22].

Iron chelators are known to have antiproliferative effects in cancer by RR inactivation [23]. RR catalyzes the rate-limiting step in DNA synthesis, which is the reductive conversion of ribonucleotides to deoxyribonucleotides [5]. RR is constructed from large RRM1 and small RRM2 subunits. RRM1 is constantly expressed throughout the cell cycle [24], while RRM2 is initiated during S-phase [24] and is degraded following M-phase [25]. The catalytic activity of RR is dependent on a dinuclear iron site in the RRM2 subunit; RRM2 requires iron for stabilization
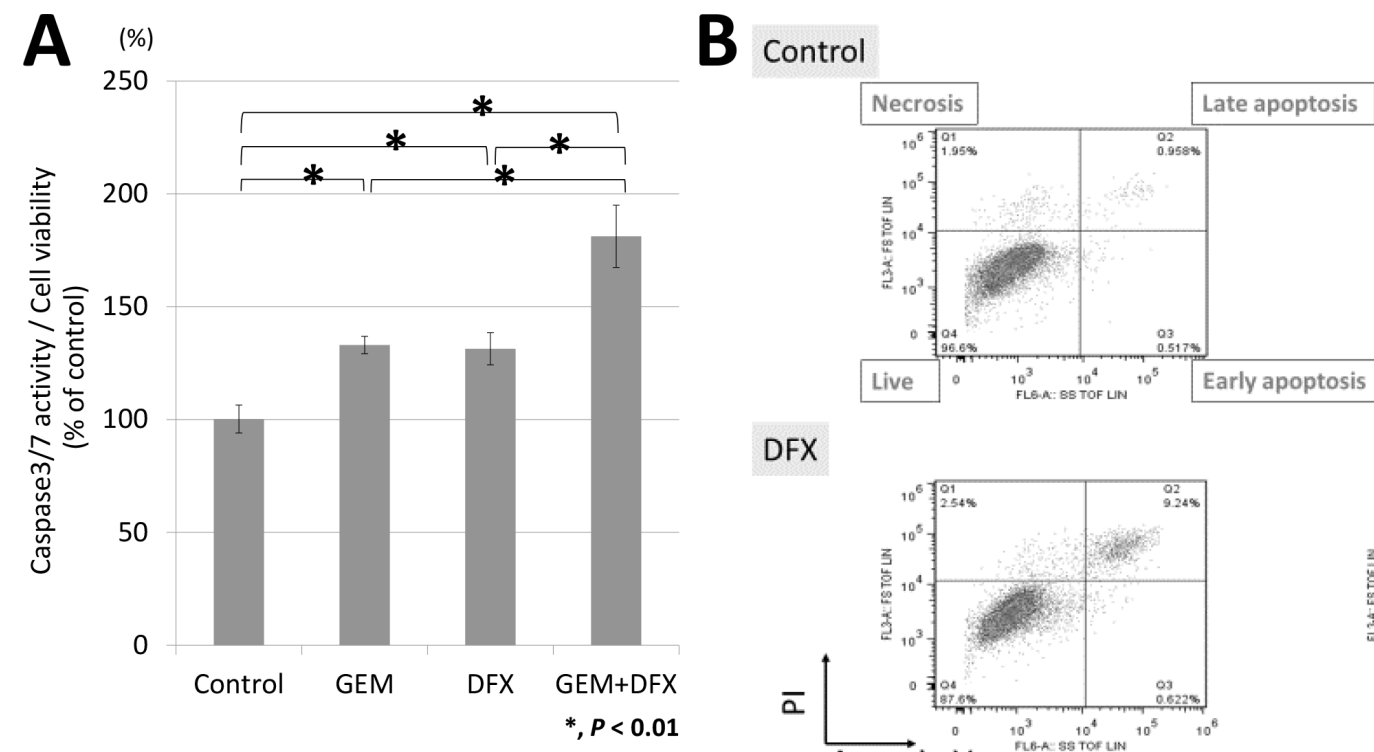

GEM
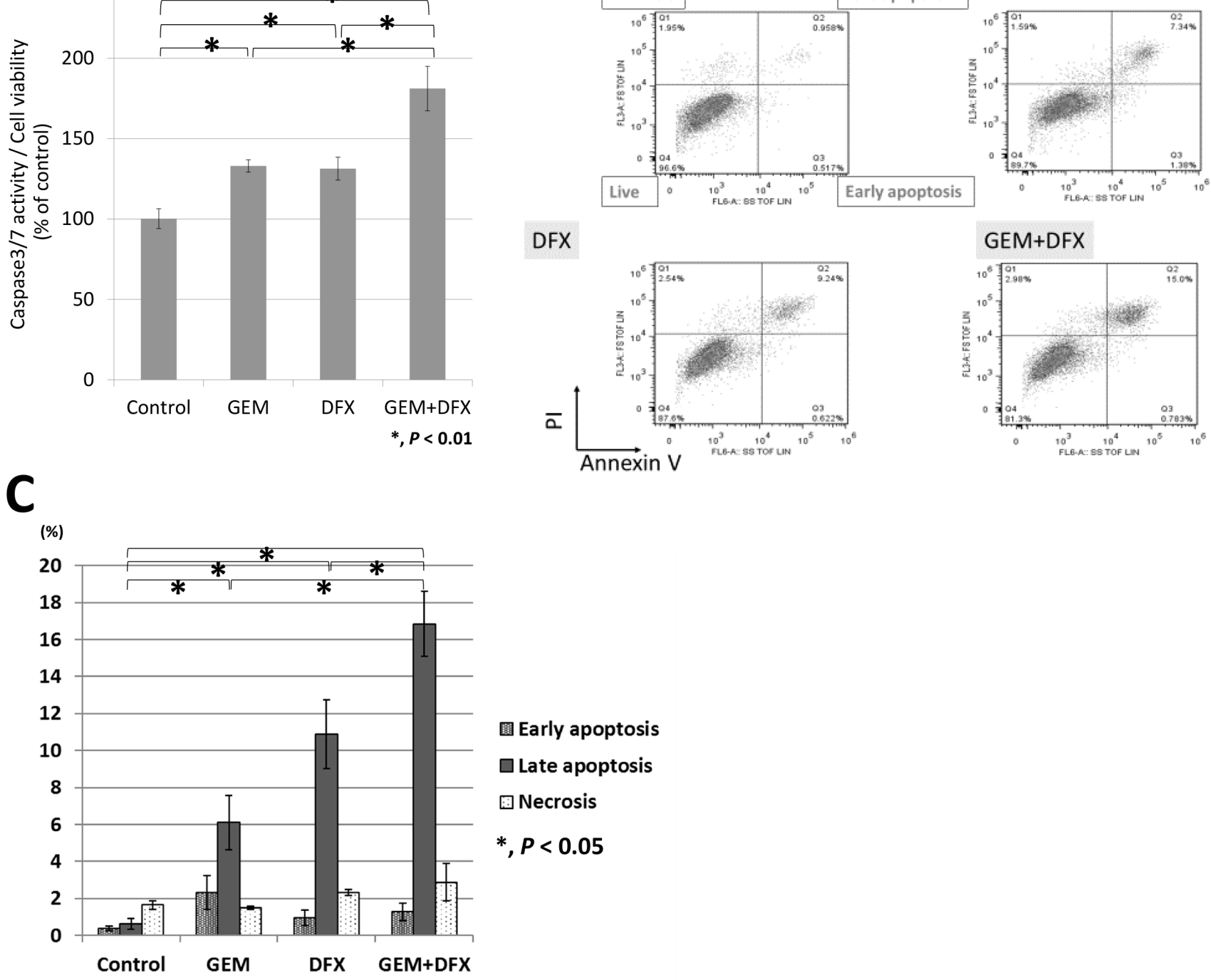

Figure 2: GEM+DFX induced apoptosis in pancreatic cancer cells in vitro. (A) The caspase $3 / 7$ activity of the combined treatment of GEM and DFX for BxPC-3 was significantly higher than that of Gem alone. Data are presented as mean \pm SD (control group: $n=6$, GEM group: $n=3$, DFX group: $n=3$, GEM+DFX group: $n=3$ ). (B) GEM, DFX, and GEM+DFX induced apoptosis in BxPC-3. (C) The number of late apoptosis cells of the combined treatment of GEM and DFX for BxPC-3 was significantly higher than that of GEM alone. Data are presented as the mean $\pm \mathrm{SD}(n=3)$. 
Table 1: Body weight of and serum biochemistries from nude mice

\begin{tabular}{|c|c|c|c|c|c|}
\hline & \multirow[b]{2}{*}{ Units } & \multicolumn{4}{|c|}{ Treatment groups } \\
\hline & & Control & GEM & DFX & GEM+DFX \\
\hline Body weight & g & $21.8 \pm 2.5$ & $22.2 \pm 2.0$ & $22.4 \pm 1.7$ & $22.3 \pm 2.3$ \\
\hline \multicolumn{6}{|l|}{ Serum biochemistry } \\
\hline Ferritin & $\mathrm{ng} / \mathrm{ml}$ & $26.8 \pm 15.1$ & $26.1 \pm 9.4$ & $16.0 \pm 4.1^{\mathrm{a}, \mathrm{b}}$ & $14.6 \pm 3.8^{\mathrm{a}, \mathrm{b}}$ \\
\hline Albumin & $\mathrm{g} / \mathrm{dl}$ & $3.6 \pm 0.2$ & $3.6 \pm 0.2$ & $3.8 \pm 0.1$ & $3.8 \pm 0.1^{\mathrm{a}, \mathrm{b}}$ \\
\hline Aspartate aminotransferase & $\mathrm{U} / 1$ & $141.7 \pm 44.6$ & $147.3 \pm 36.1$ & $132.8 \pm 37.4$ & $139.2 \pm 28.5$ \\
\hline Alanine transaminase & $\mathrm{U} / 1$ & $25.9 \pm 9.4$ & $26.3 \pm 10.2$ & $27.0 \pm 7.1$ & $30.9 \pm 8.5$ \\
\hline Creatinine & $\mathrm{mg} / \mathrm{dl}$ & $0.13 \pm 0.05$ & $0.13 \pm 0.04$ & $0.10 \pm 0.00$ & $0.10 \pm 0.00^{\mathrm{a}}$ \\
\hline Amylase & $\mathrm{U} / 1$ & $907.5 \pm 146.0$ & $841.7 \pm 74.9$ & $894.8 \pm 139.8$ & $951.9 \pm 112.2$ \\
\hline
\end{tabular}

${ }^{\mathrm{a}} p<0.05$ vs control.

${ }^{\mathrm{b}} p<0.05$ vs GEM.

Mice treated with GEM+DFX had significantly suppressed xenograft tumor growth without serious side effects, such as weight loss or altered serum biochemistry. Mice treated with DFX and GEM+DFX had significantly decreased serum ferritin levels compared with those treated with the vehicle control and GEM.

[26]. Thus, RR regulation involves the control of RRM1 and RRM2 activity and expression [27]. The absence of a constant supply of iron to RRM2 results in RRM1 inactivation [2]. Moreover, a previous study reported a synergistic effect between hydroxyurea, a RR inhibitor, and gemcitabine on gemcitabine-resistant cells [28]. However, the effect of iron chelators on RRM1 and RRM2 expression has not been studied in detail [27].
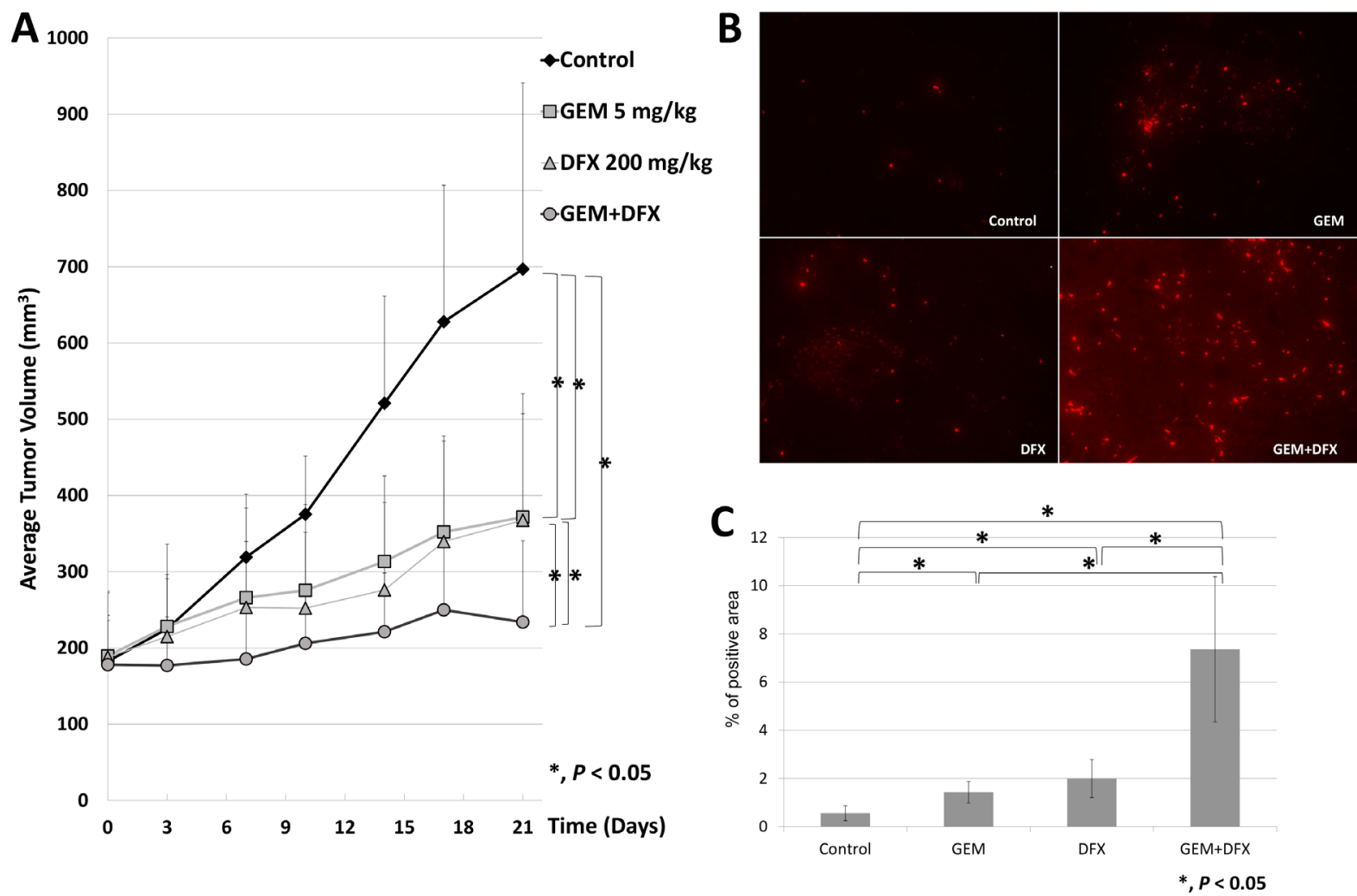

Figure 3: GEM+DFX suppressed tumor growth and induced apoptosis without any serious side effects in vivo. (A) Data are presented as mean $\pm \mathrm{SD}$. The average tumor volumes of the mice treated with vehicle control, GEM, DFX, and GEM+DFX were 697 $\pm 244,372 \pm 136,372 \pm 166$, and $234 \pm 107 \mathrm{~mm}^{3}$, respectively. The mice treated with GEM+DFX had a significantly suppressed xenograft tumor growth. (Control, $n=10$; GEM, $n=12$; DFX, $n=10$; and GEM+DFX, $n=12$ ). (B) Tumor cells were assessed for apoptosis using a TUNEL kit, which labels apoptotic nuclei with a fluorescent maker. (Magnification, $\times 200)$. (C) Tumor cells from the mice treated with GEM+DFX showed an obvious increase in apoptosis. The TUNEL stain-positive area was counted using Dynamic cell count BZ-HIC software (model BZ-9000; Keyence Co., Osaka, Japan). 
To address gemcitabine resistance and pancreatic cancer cell proliferation, we conducted an in vitro and in vivo study to assess the antiproliferative activity of the combined treatment of GEM+DFX. We found that GEM+DFX could inhibit pancreatic cancer cell proliferation and induce apoptosis in vitro and in vivo. Moreover, we confirmed that RRM1 and RRM2 protein expressions in cells incubated with DFX and GEM+DFX were significantly lower than those in the control cells in vitro.

Therefore, DFX not only demonstrated antiproliferative activity by suppressing RR expression and activity but also potentiated the effect of GEM by decreasing the competition between GEM and deoxycytidine triphosphate (Figure 6). Moreover, as iron chelators are not classified as anticancer drugs and are primarily used for iron-overload disease, GEM+DFX showed therapeutic advantages without serious side effects over single-agent GEM. Considering that more than half of patients with pancreatic cancer are diagnosed

\section{A}

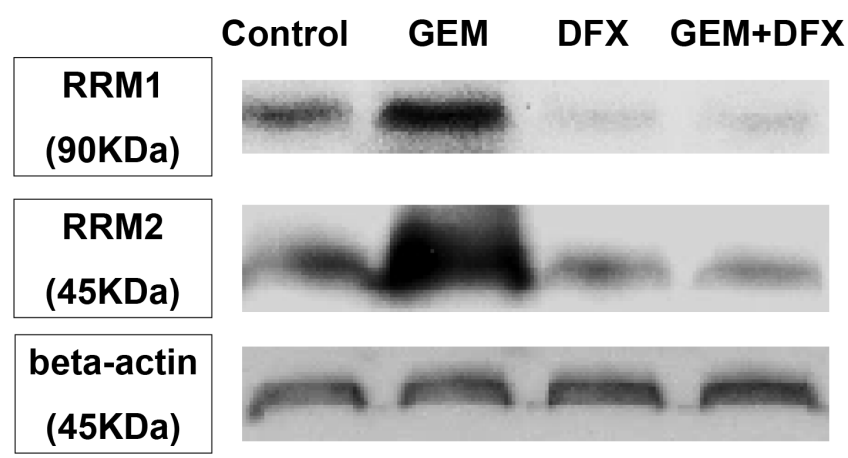

at an age of $\geq 65$ years [1], treatment with GEM+DFX possibly has favorable outcomes in clinical chemotherapy. Furthermore, this therapeutic method might turn out to be applied to other cancer like non-small cell lung cancer, ovarian cancer and bladder cancer in future. In addition, combination chemotherapies, such as regimens combining DFX, GEM, and albumin-bound paclitaxel, possibly have therapeutic advantages over albumin-bound paclitaxel with GEM in pancreatic cancer. Furthermore, a synergistic effect between DFX and fluorouracil, used in FOLFIRINOX on pancreatic cancer, in pancreatic cancer could be expected.

In conclusion, the combination therapy using GEM+DFX has significant anticancer effects through the suppression of RR activity by DFX without any serious side effects, which in turn indicates the potential of this new pancreatic cancer therapy using iron chelators and GEM as well as iron chelators and antimetabolites.

B
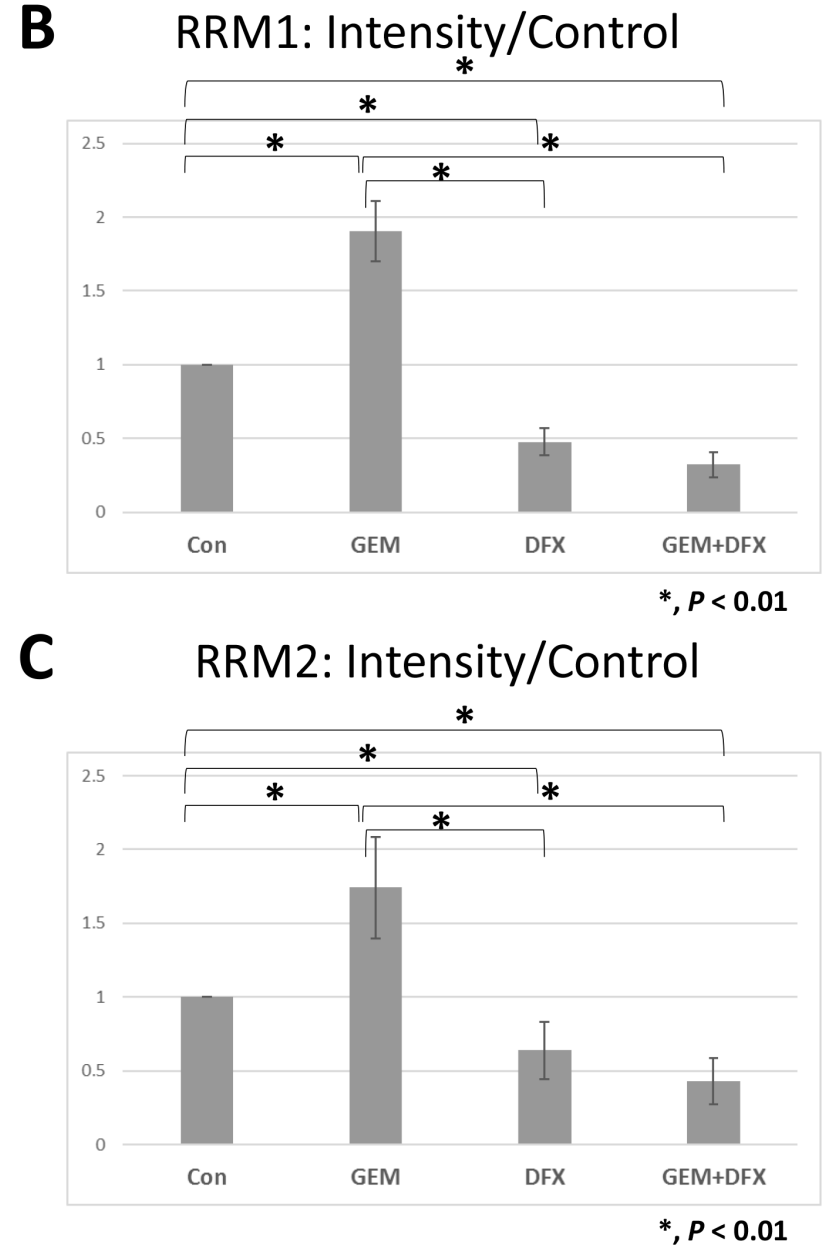

Figure 4: DFX suppressed RRM1 and RRM2 protein expression levels. The average RRM1 protein band intensity (intensity/ control) of the GEM, DFX, and GEM+DFX groups were $1.90 \pm 0.20,0.48 \pm 0.09$, and $0.32 \pm 0.08$, respectively. The average RRM2 protein band intensity (intensity/control) of the GEM, DFX, and GEM+DFX groups were $1.74 \pm 0.34,0.64 \pm 0.19$, and $0.43 \pm 0.16$, respectively. RRM1 and RRM2 expression levels significantly upregulated in the cells treated with GEM, but were significantly downregulated in the cells treated with DFX and GEM+DFX. Data are presented as mean $\pm \operatorname{SD}(n=4)$. 


\section{MATERIALS AND METHODS}

\section{Cell culture}

We reported that DFX shows antiproliferative activity against BxPC-3, a pancreatic cancer cell line [8]. In this study, we also used BxPC-3 and Panc-1 obtained from the American Type Culture Collection (Manassas, VA, USA). BxPC-3 and Panc-1 are an epithelial cell line derived from pancreatic adenocarcinoma. BxPC-3 cells were grown in RPMI-1640 (Life Technologies, Carlsbad, CA, USA) with $10 \%$ (v/v) fetal calf serum and $50 \mu \mathrm{g} / \mathrm{ml}$ gentamicin. Panc-1 cells were grown in Dulbecco's Modified Eagle's Medium (Life Technologies) with 10\% $(\mathrm{v} / \mathrm{v})$ fetal calf serum and $50 \mu \mathrm{g} / \mathrm{ml}$ gentamicin. All cells were incubated at $37^{\circ} \mathrm{C}$ in a humidified atmosphere containing $5 \% \mathrm{CO}_{2}[8]$.

\section{Reagents}

GEM (Gemzar) was purchased from Eli Lilly and Co. (Indianapolis, IN, USA), while the oral iron chelator
DFX was purchased from Novartis (Basel, Switzerland). For in vitro studies, GEM and DFX were used by dilution in culture media containing $10 \%$ fetal calf serum. For in vivo studies, GEM was dissolved in $15 \%$ propylene glycol $/ 0.9 \%$ saline, while DFX was dissolved in a sodium chloride solution $(0.9 \% \mathrm{w} / \mathrm{v}$; Chemix Inc., Shinyokohama Kohoku-ku, Yokohama, Japan) [8].

\section{Cell proliferation}

Cellular proliferation was evaluated using the MTS assay. Cell suspensions ( 3000 cells/ $100 \mu \mathrm{l})$ were added to each well in a 96-multiwell culture plate (BD Bioscience, San Jose, CA, USA) and incubated at $37^{\circ} \mathrm{C}$ for $24 \mathrm{~h}$. GEM $(0,5,10,20,39,78,156,312 \mathrm{nM})$ and/or $\operatorname{DFX}(0,1,2,4$, $8,16,31,63,125,250,500,1000 \mu \mathrm{M})$ was subsequently added to each well, and the cells were incubated for a further $72 \mathrm{~h}$. At the end of the culture period, $10 \mu \mathrm{l}$ of MTS solution (Promega, Madison, WI, USA) was added to each $100 \mu \mathrm{l}$ of culture media, which were incubated for $2 \mathrm{~h}$. Absorbance at $490 \mathrm{~nm}$ was measured with a multimode reader (Infinite 200 PRO, Tecan Trading,
A

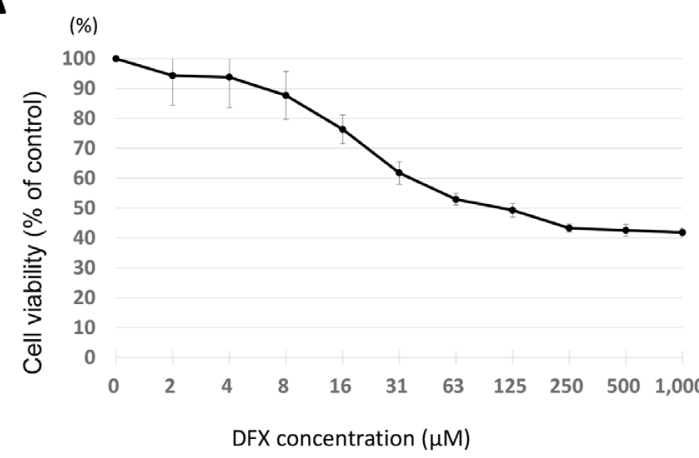

C

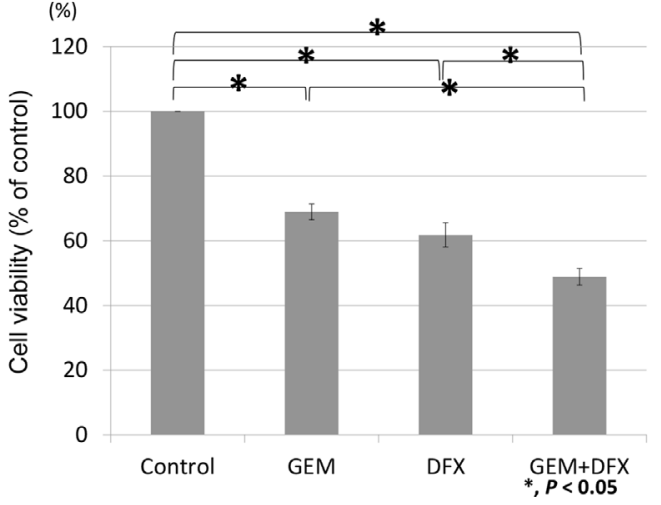

B

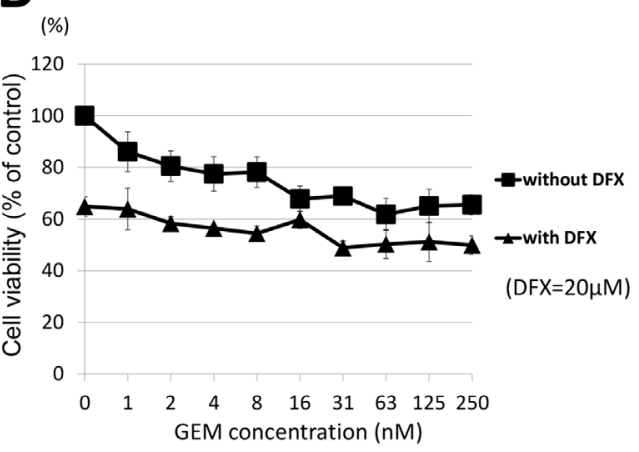

D

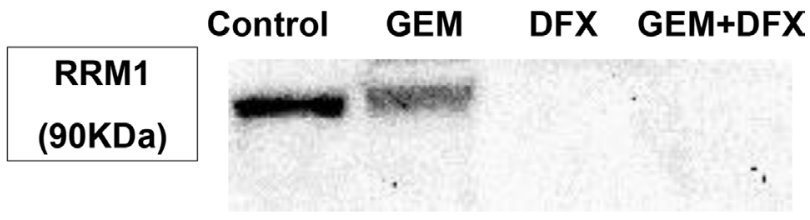

Figure 5: Panc-1 showed same trend as BxPC-3 in antiproliferative activity and RRM1 protein expression levels. (A) DFX inhibited the proliferation of Panc-1 cells. The cells were treated with DFX for $72 \mathrm{~h}$. The viability of Panc-1 cells incubated with DFX decreased in a dose-dependent manner. Data are presented as mean $\pm \mathrm{SD}(n=3)$. (B) GEM and GEM+DFX inhibited the proliferation of Panc-1 cells. The cells were treated with GEM and/or DFX for $72 \mathrm{~h}$. The viability of Panc-1 cells incubated with GEM and/or DFX decreased in a dose-dependent manner. Data are presented as mean $\pm \mathrm{SD}(n=3)$. (C) The antiproliferative activity of the combined treatment of $20 \mathrm{nM}$ GEM and $20 \mu \mathrm{M}$ DFX for Panc-1 was significantly higher than that of GEM alone. Data are presented as mean \pm SD $(n=3)$. (D) RRM1 protein expression levels of Panc-1 were down-regulated in the cells treated with DFX and GEM+DFX. But the RRM1 protein expression levels were also slightly down-regulated in the cells treated with GEM. 
AG, Switzerland), and the results were expressed as the percentage viable with respect to the untreated control $[8,19]$.

\section{Apoptosis analysis by luminescence assay and flow cytometry}

For apoptosis analysis, cell suspensions (3000 cells $/ 100 \mu \mathrm{l})$ were added to each well in a 96-multiwell culture plate (BD Bioscience) and incubated at $37^{\circ}$ $\mathrm{C}$ for $24 \mathrm{~h}$. GEM $(20 \mathrm{nM})$ and/or DFX $(20 \mu \mathrm{M})$ was added to each well, and the cells were incubated for a further $72 \mathrm{~h}$. After harvesting, caspase activity was measured using the caspase $3 / 7$ assay kit (CaspaseGlo 3/7 kit, Promega) according to the manufacturer's instructions. Apoptosis was evaluated with an apoptosis detection kit (Annexin V Apoptosis Detection Kit APC, eBioscience, San Diego, CA, USA) according to the manufacturer's instructions. After staining, the cells were examined using a flow cytometer (Gallios, Beckman Coulter, Fullerton, CA, USA). The data were analyzed by FlowJo software (Tree Star, Inc., Ashland, OR, USA) [8, 19].
Tumor xenografts in nude mice

Animal care was performed in accordance with the animal ethics requirements at Yamaguchi University School of Medicine, and the experimental protocol was approved by the institutional animal care and user uommittee (approval ID 21-035). Female BALB/c (nu/ nu) mice were purchased from Nippon SLC (Shizuoka, Japan) and were housed in sterile conditions. Experiments commenced when the mice were 8-10 weeks of age. $\mathrm{BxPC}-3$ cells in culture were harvested and resuspended in a 1:1 ratio of RPMI-1640 and Matrigel (BD Bioscience). Viable cells $\left(3 \times 10^{6}\right.$ cells $)$ were administered subcutaneously into the back of the mice.

After engraftment, tumor size was measured using vernier calipers every 2 days, and tumor volume $\left(\mathrm{TV} ; \mathrm{mm}^{3}\right)$ was calculated using the following formula: $T V=d^{2} \times D / 2$, where $\mathrm{d}$ and $\mathrm{D}$ are the shortest and the longest diameter, respectively. When the average TV reached approximately $180 \mathrm{~mm}^{3}$, drug administration began (day 0).

The mice were divided into four groups: control $(n=10), \operatorname{GEM}(n=12), \mathrm{DFX}(n=10)$, and GEM+DFX $(n=12)$ groups. The treatment administration schedule

\section{Ribonucleotilde reductase (RR) and Gemcitabine and iron chelator}

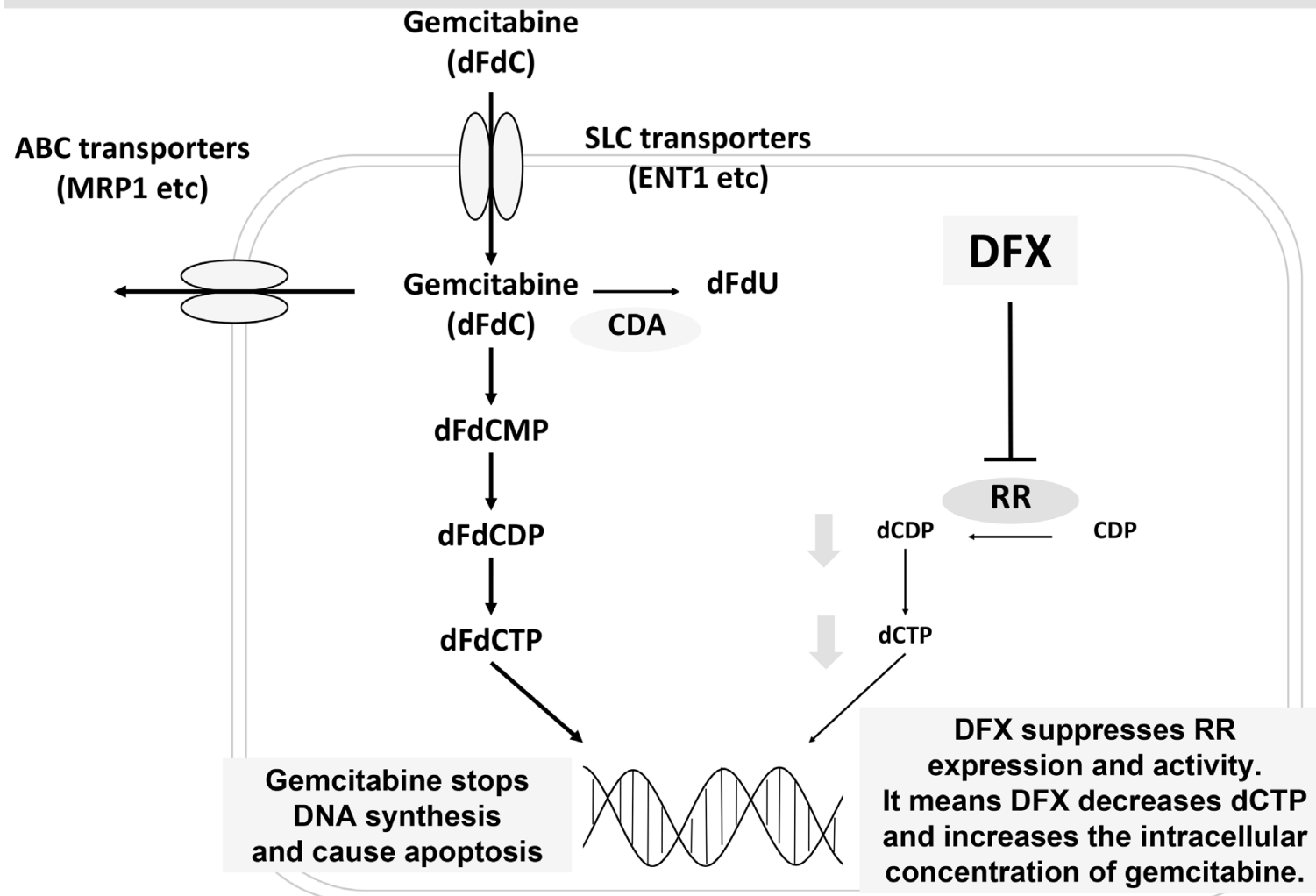

Figure 6: DFX suppressed RR expression and activity and potentiated the effect of GEM. DFX not only demonstrated antiproliferative activity by suppressing RR expression and activity but also potentiated the effect of GEM by decreasing the competition between GEM and deoxycytidine. 
was based on our past study [8] and a previous study [29]. The DFX and GEM+DFX groups received DFX, which was administered by oral gavage every 2 days, with three treatments per week, for 21 days at a concentration of $200 \mathrm{mg} / \mathrm{kg}$. The control and GEM groups received vehicle alone (PBS), which was also administered by oral gavage. The GEM and GEM+DFX groups received GEM, which was administered intraperitoneally every 3 days, with two treatments per week, for 21 days at a concentration of 5 $\mathrm{mg} / \mathrm{kg}$. The control and DFX groups received vehicle alone (PBS), which was also administered intraperitoneally.

At the end of the experiment, the mice were sacrificed, and the tumors were excised and processed for TUNEL staining. Blood samples were collected simultaneously during tumor removal. Serum ferritin levels were measured using the enzyme-linked immunoassay method (Mouse Ferritin ELISA kit, Kamiya Biochemical Company, Seattle, WA, USA). Serum biochemistries other than ferritin were analyzed by Yamaguchi Laboratory Co., Ltd. (Ube, Japan) [8].

\section{Histology and TUNEL staining}

Tumor sections (3-mm-thick) were fixed in 4\% paraformaldehyde (Muto Pure Chemicals, Tokyo, Japan) for $72 \mathrm{~h}$ and paraffin embedded. Apoptotic tumor cells were detected by TUNEL staining using an In Situ Detection kit (TMR Red; Roche Diagnostics, Indianapolis, IN, USA) according to the manufacturer's protocol. The TUNEL stain-positive area was measured using Dynamic cell count BZ-HIC software (model BZ-9000; Keyence Co., Osaka, Japan).

\section{Western blot analysis}

BxPC-3 and Panc- 1 cells were treated with $20 \mathrm{nM}$ of GEM and/or $20 \mu \mathrm{M}$ of DFX for $72 \mathrm{~h}$. The cells were homogenized in lysis buffer on ice. Suspensions were incubated for $1 \mathrm{~h}$ at $4^{\circ} \mathrm{C}$ and centrifuged at $15,000 \times \mathrm{g}$ for $30 \mathrm{~min}$ at $4^{\circ} \mathrm{C}$. The collected supernatants were used for western blotting after protein concentration measurement using the Lowry method [30]. The samples from BxPC-3 cells were prepared three times independently.

For western blotting, $40 \mu \mathrm{g}$ of protein was used. Sodium dodecyl sulfate-polyacrylamide gel electrophoresis was performed in pre-cast gels $(12 \%$ acrylamide; MiniPROTEAN TGX Gels, Bio-Rad, Hercules, CA, USA). The primary antibodies were as follows: rabbit monoclonal antibody against ribonucleotide reductase (RR) subunit 1 (RRM1, dilution 1:3000, ab137114; Abcam, Cambridge, MA, USA), rabbit monoclonal antibody against RR subunit 2 (RRM2, dilution 1:1500, ab172476; Abcam), and mouse monoclonal antibody against beta-actin (dilution 1:10000, ab6276; Abcam). Membranes were incubated with the primary antibodies overnight at $4^{\circ} \mathrm{C}$, washed three times with PBS containing $0.05 \%$ Tween-20 and once with PBS, and incubated with a horseradish peroxidaseconjugated secondary antibody (dilution 1:5000; GE Healthcare, Buckinghamshire, England, UK) for $1 \mathrm{~h}$ at room temperature [31]. Protein bands were quantitated by densitometric analysis using image analysis software (Quantity One; BioRad, Hercules, CA, USA).

\section{Statistical analysis}

Statistical significance was determined using Student's $t$ test or analysis of variance. JMP 13 statistical software (SAS Institute Inc., Cary, NC, USA) was employed in the analysis. Results are expressed as mean \pm standard deviation (SD), and differences with $p<0.05$ were considered statistically significant.

\section{Author contributions}

Shuhei Shinoda and Taro Takami performed most of the experiments. Shogo Amano and Hirofumi Harima performed Cell proliferation, Apoptosis analysis and Tumor xenografts in nude mice. Toshihiko Matsumoto, Koichi Fujisawa and Naoki Yamamoto performed Histology, TUNEL staining and Western blot analysis. Shuhei Shinoda, Seiji Kaino and Taro Takami designed the study, analysed the data and wrote the paper. Takahiro Yamasaki and Isao Sakaida provided financial support and final approval of the manuscript. All authors approved and commented on the manuscript.

\section{ACKNOWLEDGMENTS}

This study was supported by the Strategic Research Promotion Program from Yamaguchi University, the Translational Research Program from Yamaguchi University Hospital, the Pancreatic Disease Research Award from the Pancreas Research Foundation of Japan, and Grants-in-Aid for Scientific Research from the Japan Society for the Promotion of Science (16H05287), the Japan Science and Technology Agency, and the Ministry of Health, Labor, and Welfare.

\section{CONFLICTS OF INTEREST}

The authors declare that they have no conflicts of interest.

\section{REFERENCES}

1. SEER. Surveillance, Epidemiology, and End Results Program: cancer statistics review 1975-2013. National Cancer Institute; 201. Available from: https://seer.cancer. gov/csr/1975_2013/.

2. Burris HA 3rd, Moore MJ, Andersen J, Green MR, Rothenberg ML, Modiano MR, Cripps MC, Portenoy RK, 
Storniolo AM, Tarassoff P, Nelson R, Dorr FA, Stephens CD, Von Hoff DD. Improvements in survival and clinical benefit with gemcitabine as first-line therapy for patients with advanced pancreas cancer: a randomized trial. J Clin Oncol. 1997; 15:2403-13.

3. Conroy T, Desseigne F, Ychou M, Bouché O, Guimbaud R, Bécouarn Y, Adenis A, Raoul JL, Gourgou-Bourgade S, de la Fouchardière $C$, Bennouna J, Bachet JB, KhemissaAkouz F, et al, and Groupe Tumeurs Digestives of Unicancer, and PRODIGE Intergroup. FOLFIRINOX versus gemcitabine for metastatic pancreatic cancer. N Engl J Med. 2011; 364:1817-25.

4. Von Hoff DD, Ramanathan RK, Borad MJ, Laheru DA, Smith LS, Wood TE, Korn RL, Desai N, Trieu V, Iglesias JL, Zhang H, Soon-Shiong P, Shi T, et al. Gemcitabine plus nab-paclitaxel is an active regimen in patients with advanced pancreatic cancer: a phase I/II trial. J Clin Oncol. 2011; 29:4548-54.

5. Kalinowski DS, Richardson DR. The evolution of iron chelators for the treatment of iron overload disease and cancer. Pharmacol Rev. 2005; 57:547-83.

6. Torti SV, Torti FM. Iron and cancer: more ore to be mined. Nat Rev Cancer. 2013; 13:342-55.

7. Yamasaki T, Terai S, Sakaida I. Deferoxamine for advanced hepatocellular carcinoma. N Engl J Med. 2011; 365:576-8.

8. Harima H, Kaino S, Takami T, Shinoda S, Matsumoto T, Fujisawa K, Yamamoto N, Yamasaki T, Sakaida I. Deferasirox, a novel oral iron chelator, shows antiproliferative activity against pancreatic cancer in vitro and in vivo. BMC Cancer. 2016; 16:702.

9. Yamamoto N, Yamasaki T, Takami T, Uchida K, Fujisawa K, Matsumoto T, Saeki I, Terai S, Sakaida I. Deferasirox, an oral iron chelator, prevents hepatocarcinogenesis and adverse effects of sorafenib. J Clin Biochem Nutr. 2016; 58:202-9.

10. Binenbaum Y, Na'ara S, Gil Z. Gemcitabine resistance in pancreatic ductal adenocarcinoma. Drug Resist Updat. 2015; 23:55-68.

11. Lecca P. Methods of biological network inference for reverse engineering cancer chemoresistance mechanisms. Drug Discov Today. 2014; 19:151-63.

12. Goan YG, Zhou B, Hu E, Mi S, Yen Y. Overexpression of ribonucleotide reductase as a mechanism of resistance to 2,2-difluorodeoxycytidine in the human $\mathrm{KB}$ cancer cell line. Cancer Res. 1999; 59:4204-7.

13. Bepler G, Kusmartseva I, Sharma S, Gautam A, Cantor A, Sharma A, Simon G. RRM1 modulated in vitro and in vivo efficacy of gemcitabine and platinum in non-small-cell lung cancer. J Clin Oncol. 2006; 24:4731-7.

14. Ceppi P, Volante M, Novello S, Rapa I, Danenberg KD, Danenberg PV, Cambieri A, Selvaggi G, Saviozzi S, Calogero R, Papotti M, Scagliotti GV. ERCC1 and RRM1 gene expressions but not EGFR are predictive of shorter survival in advanced non-small-cell lung cancer treated with cisplatin and gemcitabine. Ann Oncol. 2006; 17:1818-25.

15. Jordheim LP, Guittet O, Lepoivre M, Galmarini CM, Dumontet C. Increased expression of the large subunit of ribonucleotide reductase is involved in resistance to gemcitabine in human mammary adenocarcinoma cells. Mol Cancer Ther. 2005; 4:1268-76.

16. Nakahira S, Nakamori S, Tsujie M, Takahashi Y, Okami J, Yoshioka S, Yamasaki M, Marubashi S, Takemasa I, Miyamoto A, Takeda Y, Nagano H, Dono K, et al. Involvement of ribonucleotide reductase M1 subunit overexpression in gemcitabine resistance of human pancreatic cancer. Int J Cancer. 2007; 120:1355-63.

17. Kontoghiorghes GJ, Piga A, Hoffbrand AV. Cytotoxic and DNA-inhibitory effects of iron chelators on human leukaemic cell lines. Hematol Oncol. 1986; 4:195-204.

18. Estrov Z, Tawa A, Wang XH, Dubé ID, Sulh H, Cohen A, Gelfand EW, Freedman MH. In vitro and in vivo effects of deferoxamine in neonatal acute leukemia. Blood. 1987; 69:757-61.

19. Saeki I, Yamamoto N, Yamasaki T, Takami T, Maeda M, Fujisawa K, Iwamoto T, Matsumoto T, Hidaka I, Ishikawa T, Uchida K, Tani K, Sakaida I. Effects of an oral iron chelator, deferasirox, on advanced hepatocellular carcinoma. World J Gastroenterol. 2016; 22:8967-77.

20. Ford SJ, Obeidy P, Lovejoy DB, Bedford M, Nichols L, Chadwick C, Tucker O, Lui GY, Kalinowski DS, Jansson PJ, Iqbal TH, Alderson D, Richardson DR, Tselepis C. Deferasirox (ICL670A) effectively inhibits oesophageal cancer growth in vitro and in vivo. $\mathrm{Br} \mathrm{J}$ Pharmacol. 2013; 168:1316-28.

21. Lui GY, Obeidy P, Ford SJ, Tselepis C, Sharp DM, Jansson PJ, Kalinowski DS, Kovacevic Z, Lovejoy DB, Richardson DR. The iron chelator, deferasirox, as a novel strategy for cancer treatment: oral activity against human lung tumor xenografts and molecular mechanism of action. Mol Pharmacol. 2013; 83:179-90.

22. Ohyashiki JH, Kobayashi C, Hamamura R, Okabe S, Tauchi $\mathrm{T}$, Ohyashiki K. The oral iron chelator deferasirox represses signaling through the mTOR in myeloid leukemia cells by enhancing expression of REDD1. Cancer Sci. 2009; 100:970-7.

23. Lui GY, Kovacevic Z, Richardson V, Merlot AM, Kalinowski DS, Richardson DR. Targeting cancer by binding iron: dissecting cellular signaling pathways. Oncotarget. 2015; 6:18748-79. https://doi.org/10.18632/oncotarget.4349.

24. Chabes A, Thelander L. Controlled protein degradation regulates ribonucleotide reductase activity in proliferating mammalian cells during the normal cell cycle and in response to DNA damage and replication blocks. J Biol Chem. 2000; 275:17747-53.

25. Thelander L, Reichard P. Reduction of ribonucleotides. Annu Rev Biochem. 1979; 48:133-58. 
26. Thelander L, Gräslund A. Mechanism of inhibition of mammalian ribonucleotide reductase by the iron chelate of 1-formylisoquinoline thiosemicarbazone. Destruction of the tyrosine free radical of the enzyme in an oxygen-requiring reaction. J Biol Chem. 1983; 258:4063-6.

27. Le NT, Richardson DR. The role of iron in cell cycle progression and the proliferation of neoplastic cells. Biochim Biophys Acta. 2002; 1603:31-46.

28. Minami K, Shinsato Y, Yamamoto M, Takahashi H, Zhang S, Nishizawa Y, Tabata S, Ikeda R, Kawahara K, Tsujikawa K, Chijiiwa K, Yamada K, Akiyama S, et al. Ribonucleotide reductase is an effective target to overcome gemcitabine resistance in gemcitabine-resistant pancreatic cancer cells with dual resistant factors. J Pharmacol Sci. 2015; 127:319-25.
29. Kovacevic Z, Chikhani S, Lovejoy DB, Richardson DR. Novel thiosemicarbazone iron chelators induce up-regulation and phosphorylation of the metastasis suppressor N-myc down-stream regulated gene 1: a new strategy for the treatment of pancreatic cancer. Mol Pharmacol. 2011; 80:598-609.

30. Lowry OH, Rosebrough NJ, Farr AL, Randall RJ. Protein measurement with the Folin phenol reagent. J Biol Chem. 1951; 193:265-75.

31. Suenaga S, Kuramitsu Y, Kaino S, Maehara S, Maehara Y, Sakaida I, Nakamura K. Active hexose-correlated compound down-regulates HSP27 of pancreatic cancer cells, and helps the cytotoxic effect of gemcitabine. Anticancer Res. 2014; 34:141-6. 